\title{
Fetal Instrumental Extractions at the Maternity Section of the Dakar Nabil Choucair Health Centre (Senegal) in 2017: Epidemio-Clinical Aspects, Indications and Prognosis
}

\author{
Omar Gassama, Babacar Biaye*, Boura Taoufiki, Ndeye Astou Faye, Djibril Diallo, \\ Aminata Niass, Abdou Ndiaye, Alassane Diouf, Jean Charles Moreau \\ Gynecological and Obstetric Clinic of Aristide Hospital Le Dantec of Dakar, Dakar, Senegal \\ Email: ^drbabacarbiaye@yahoo.fr
}

How to cite this paper: Gassama, O., Biaye, B., Taoufiki, B., Faye, N.A., Diallo, D., Niass, A., Ndiaye, A., Diouf, A. and Moreau, J.C. (2020) Fetal Instrumental Extractions at the Maternity Section of the Dakar Nabil Choucair Health Centre (Senegal) in 2017: Epidemio-Clinical Aspects, Indications and Prognosis. Open Journal of Obstetrics and Gynecology, 10, 390-399.

https://doi.org/10.4236/ojog.2020.1030035

Received: February 7, 2020

Accepted: March 23, 2020

Published: March 26, 2020

Copyright () 2020 by author(s) and Scientific Research Publishing Inc. This work is licensed under the Creative Commons Attribution International License (CC BY 4.0).

http://creativecommons.org/licenses/by/4.0/

\section{Abstract}

Introduction: An instrumental extraction is performed in order to shorten the phase of expulsion of the fetus outside the maternal pelvic pathway, when there is a suspected fetal state or a defect in progression of the fetal mobile. It can be responsible for immediate or late maternal complications, which are not specific because they can occur after a normal delivery. The objectives of this work are to describe the epidemiological-clinical and prognosis aspects of deliveries assisted by instrumental extractions in a reference maternity unit in Dakar. Materials and Methods: This was a retrospective, descriptive and analytical study between January 1, 2017 and December 31, 2017, a period of 12 months at the maternity ward of the Nabil Choucair Health Center. The collection was carried out using the survey form completed on the basis of the analysis of the files, the delivery register and the anaesthesia register of the operating room. The parameters studied were about socio-demographic characteristics, indications and prognosis. The data entry was carried out using the Sphinx version 5 software and the data analysis using the Epi info version 3.5 software. Results: During the period of our study, we collected 94 instrumental extractions. The frequency of instrumental extractions was $1.7 \%$. The average age of the patients was 25 years with extremes of 16 to 43 years old. The average parity was 1 with extremes 1 to 6 . Among parturient women, 12 patients $(12.8 \%)$ had a history of suction cup, two $(2.1 \%)$ had received forceps and three (3.2\%) had a cesarean section. The average gestational age was 39 Weeks of Amenorrhea (WA), the average uterine height was $32 \mathrm{~cm}$, fetal heart sounds were normal in $98 \%$ parturient' cases. The vaginal touch had found a fully dilated cervix, a rupture of the amniotic sac with clear 
amniotic fluid in $98 \%$ of parturient women and a fetus with an anterior left iliac occipito topin $69.4 \%$ of cases. The pelvis was clinically normal in all parturient women. The indications were dominated by maternal fatigue (65.9\%). The spatula was the most commonly used instrument (82.7\%). Episiotomy was performed in $97.3 \%$ of cases. The average weight of the newborn was 3058 grams and an Apgar score of 8/10 was noted in 96\% of newborns. We noted 3 cases of maternal complications with perineal tear type (3.2\%) and 1 case of perineal tear associated with postpartum hemorrhage $(1.06 \%)$. The neonatal prognosis was dominated by 2 caput succedaneum cases $(2.1 \%)$. Newborns were alive and well in 97.8\%. We noted 2 cases of death, i.e. $2.1 \%$ in unsolved circumstances. All the mothers were alive and well at (100\%). Conclusion: Instrumental extractions must be integrated into our structures to significantly reduce the number of abusive cesarean sections. The perfect mastery of extraction techniques and indications makes it possible to reduce fetal suffering while avoiding the morbidity associated with instrumental extractions.

\section{Keywords}

Instrumental Extraction, Suction Cup, Spoonbill, Forceps

\section{Introduction}

Childbirth is the set of mechanical, dynamic and plastic phenomena that result in the release of the newborn and its appendages from the maternal genital tract, from the twenty-second week of amenorrhea or a newborn weighing more than $500 \mathrm{~g}$ [1] [2]. Fetal expulsion can be assisted by instrumental extraction. The latter can be defined as the assistance at the birth of a child living by natural means or at the end of a caesarean section by means of an adapted instrument such as: the forceps, the suction cup or Thierry's spatulas. Instrumental extraction is performed to shorten the expulsive phase of the fetus out of the maternal genital tract [3]. A gradual decrease in instrumental extractions has been observed since the 1970s in obstetric practice [4] [5]. In Senegal, in a national survey, instrumental forceps extractions accounted for $11.2 \%$ of obstetric interventions in $1992,8.6 \%$ in 1996 and 3.9\% in 2001 [6]. They accounted for $0.09 \%$ in 1992 , $0.05 \%$ in 1996 of births at the national level [6]. We conducted this study to analyze our practice in instrumental extraction. The objectives were to describe the epidemiological-clinical aspects and to evaluate the maternal and perinatal prognosis of our instrumental extraction's deliveries in a reference maternity clinic in Dakar.

\section{Patients and Methods}

Our study was carried out in the Maternity section of the Nabil Choucair Health Center located in the city of Dakar. 
It was a retrospective, descriptive and analytical study carried out over the period from January 1, 2017 to December 31, 2017, i.e. a period of twelve months.

All women who gave birth by instrumental extraction during our study period were included in this study.

Incomplete files were secondarily excluded from the study.

For each parturient, the parameters studied were recorded on a survey sheet which collected socio-demographic characteristics, history, clinical examination, indications, neonatal parameters and maternal-fetal complications. The information was gathered through an examination of birth registers, notebooks for surgical reports and anesthesia records.

Data entry was carried out using Sphinx version 5 software and data analysis using Epi info version 3.5 software. All ethical measures have been taken for this study.

\section{Results}

\subsection{Frequency}

We collected 94 instrumental extractions out of 5342 deliveries from 1 January 2017 to 31 December 2017, i.e. an 12 month period in the Maternity Section of the Nabil Choucair Health Centre in Dakar, or a frequency of $1.7 \%$.

\subsection{Socio-Demographic Characteristics}

The average age was 25.4 years with extremes of 16 and 43 years.

The average gestation status was 1.6 gestations at the extremes of 1 and 6 gestations.

The patients were mainly primigravida (69.9\%) as reported in Table 1.

The average parity was 1.4 pares with extremes $1 / 6$. More than $3 / 4$ of the patients $(80.9 \%)$ were primipares. For parity, primiparous women were in the majority (80.9\%). Concerning marital status, the majority of our parturient women were married (97.8\%).

\subsection{Admission Procedures for Patients}

In our series, $74.4 \%$ of patients came on their own and $24(25.6 \%)$ were evacuated by other health structures.

Table 1. Distribution of patients by gestation $(n=94)$.

\begin{tabular}{ccc}
\hline Gestation Status & Size & Percentage \\
\hline Primigravida & 65 & 69.9 \\
Paucigests & 12 & 12.9 \\
Multigestes & 10 & 10.8 \\
Large multi-gestation & 7 & 7.5 \\
Total & 94 & 100 \\
\hline
\end{tabular}




\subsection{Clinical Examination on Admission}

In the history, 3 patients (3.2\%) had received a cesarean section, 12 patients (12.8\%) had received suction cups and 26 patients $(27.7 \%)$ had a history of abortions. At prenatal follow-up, (96.8\%) of the patients had 4 prenatal consultations and prenatal follow-up was regular. At admission, the general condition was good in the majority of parturient women (97.8\%), the average age of pregnancy was 39 weeks of amenorrhea (WA) with extremes of 34 and 42 SA, the average uterine height was $32 \mathrm{~cm}$ with extremes of 28 and $40 \mathrm{~cm}$. Fetal heart sounds were perceived in all patients. The vaginal touch found a fully dilated cervix with a cephalic presentation engaged in the lower part in all parturient women, an amniotic sac ruptured with clear amniotic fluid in $65.9 \%$ of them, a fetus with an anterior left iliac occipito top presentation in $(63.8 \%)$ of cases. Episiotomy was performed in $97.3 \%$ of parturient women and the pelvis was clinically normal in all parturient women.

\subsection{Technical}

The spatula was the main extraction instrument used (82.7\%) followed by the suction cup with $(13.3 \%)$. Fetal extraction by spatula was most often done by direct occipito-pubic extraction in 70 parturients $70 \%$ followed by occipito-sacral extraction in 7 (7.4\%) parturients. Fetal extraction by suction cup was found in 13 parturients (13.3\%) (Table 2). The intake was respectively in occipito-pubic in $10(10.6 \%)$ parturients and in occipito-sacral in $3(3.19 \%)$ of them.

Table 2. Distribution by position variety $(n=94)$.

\begin{tabular}{ccc}
\hline Variety of position & Size & Percentage \\
\hline anterior left occipito-iliac & 60 & 63.8 \\
anterior right occipito-iliac & 25 & 26.5 \\
posterior right occipito-iliac & 05 & 5.3 \\
posterior left occipito-iliac & 04 & 4.2 \\
TOTAL & 94 & 100 \\
\hline
\end{tabular}

Table 3. Distribution of women according to indications $(n=94)$.

\begin{tabular}{ccc}
\hline Indications & Size & Percentage \\
\hline Maternal fatigue & 62 & 65.9 \\
Stop the progress & 15 & 15.9 \\
Fetal suffering & 09 & 9.5 \\
Scar uterus & 04 & 4.2 \\
Eclampsia & 02 & 2.1 \\
Prematurity & 02 & 2.1 \\
Total & 94 & 100 \\
\hline
\end{tabular}




\subsection{Partogram}

Partogram use was noted in more than $4 / 5$ of patients (88\%).

The indications were dominated by expulsion assistance for maternal fatigue in $65.9 \%$ of cases followed by stopping the progression of the fetal mobile in $15.9 \%$ and acute fetal suffering in $9.5 \%$. All spatula (77) and forceps (4) applications were performed by physicians (Table 3 ). On the other hand, for the suction cup, 13 of them were performed by midwives (6.4\%) and 7 by doctors $(7.4 \%)$.

\subsection{Neonatal Parameters}

The average weight of the newborn was 3058 grams with extremes of 1100 and 4400 grams, an Apgar score equal to 8 in $96 \%$ of newborns. Fetal complications were noted in $4 \%$ or 3 cases and the types of complications were not mentioned in the data.

\subsection{Prognostic Aspects}

Maternals: We have not recorded any maternal deaths. We noted perineal traumas such as episiotomies (80.6\%), perineal tears (4\%) ranging from first degree to third degree without affecting the internal sphincter. Finally, a case of perineal tearing associated with postpartum hemorrhage has been reported.

Neonatals: Newborns were alive and well in $97.9 \%$ of cases. There were 2 cases of death or $2.12 \%$. In our series were noted 2 cases $(2.1 \%)$ of caput succedaneum.

\section{Discussion}

\subsection{Socio-Epidemiological Characteristics}

Since the 1970s, instrumental extractions have declined significantly worldwide. In our experience at the Nabil Choucair Health Center in Dakar, the average rate is $1.7 \%$. Studies conducted in Senegal under the same socio-economic conditions have also shown a gradual decline over the years: $1.6 \%$ in 1996, 1.38\% in 2008 [7] [8]. At the same time, the caesarean section rate has increased: $11 \%$ of deliveries in 2006, 15.5\% in 2007 and $17.5 \%$ in 2008 . We have already made the same observations [7] in a study conducted at the gynecological and obstetric clinic of Aristide Le Dantec Hospital between 1992 and 1996, with a rate of 1.6\% of deliveries by forceps and an increase in the cesarean section rate from $12 \%$ of deliveries in 1992 to $17.5 \%$ in 1996. This low rate of instrumental extractions is also found in other African series [6] [9] [10] [11] [12]. There are several reasons that may explain this gradual decline in instrumental extractions use in our obstetrical practice:

- Extraction instruments are not always available in maternity wards;

- Midwives are less and less trained in these delivery techniques because of their rarity;

- The use of oxytocics is better codified in the treatment of rotation or expulsion defects related to dynamic dystocia; 
- Caesarean section surgery has become a common intervention nowadays; its indications have expanded considerably, especially in the direction of the fetal interest.

At the national level, in a survey of emergency obstetric and neonatal care from 2012 to 2013 , the cesarean section rate was $4.4 \%$ compared to $0.2 \%$ for instrumental extractions [13]. The epidemiological profile of women giving birth by instrumental extraction in Dakar is that of a young primiparous woman (average age 25 years), carrying a full-term pregnancy. This epidemiological profile is comparable to the series reported in other maternity hospitals in Senegal [6] [7], Côte d'Ivoire [11], Tunisia [12]. The epidemiological profile of patients who received instrumental extractions at the Nabil Choucair Health Centre in Dakar is that of a young primiparous woman (69.9\%) whose average age was 25 years, most of these type of women were married $(97.8 \%)$. This profile is similar to that found by Sow [14] in 2013, who reported $64.4 \%$ of primiparous women, with an average age of 25 years. This epidemiological profile has some particularities compared to those found in the European series. Indeed, Troyer [15] in Marseille reported an average age of 28 years and $80 \%$ of primipares. In developed countries, lack of awareness of pushing efforts due to lack of preparation for childbirth, maternal fatigue and systematic use of epidural anaesthesia during childbirth may partly explain the prevalence of primiparous women [16].

\subsection{Clinical Aspects}

In our series, the average age of pregnancy at the time of extraction was 39 weeks of amenorrhoea (WA) with extremes of 34 and 42 . Other authors had found the same results [17] [18]. The history of cesarean sections had been found in 4 patients (4.3\%). In 2015, Cissé had found the same frequency [19]. The prevention of uterine dehiscence is the main indication in the case of a scarred uterus. The pelvis was clinically normal in all parturient women with $100 \%$ of cases. Normal basins were also in the majority in Diouf's study with a frequency of $89.6 \%$ [8]. The partogram was used in the majority of cases (88\%) in work supervision. According to the French national college of obstetricians and gynecologists, the systematic and correct use of the partogram is accompanied by a reduction in the number of forceps, but not the suction cup [12].

\subsection{Indications, Operating Technique, Type of Instrument}

In our series, the indications were mainly dominated by maternal fatigue in $65.9 \%$ and stopping the progression of fetal mobility in (15.9\%) cases. The predominance of indications related to maternal fatigue is reported by several authors in instrumental extractions [6] [16]. In our study, the spatula was the most commonly used instrument with $82.7 \%$ of instrumental deliveries compared to $13.7 \%$ of suction cup and $4 \%$ of forceps. Diouf in Senegal had objected $50.9 \%$ of suction cup to $49.1 \%$ of forceps [8]. Our results are different from the data in the literature. This is explained by the fact that the spatula was the instrument 
available during our study. Fetal extraction by spatula was most often done by direct occipito-pubic extraction in $70(70 \%)$ parturients followed by occipito-sacral extraction in 7 (7.4\%) parturients. Cissé in Senegal found (50.7\%) in occipito-pubic position and (8.1\%) occipito-sacral-position [7]. These 2 results are superimposable in terms of percentage but differ according to the type of instrument. In our series, the spatula was available during our study. Acute fetal suffering ranks third in our series of indications with a frequency of $9.5 \%$; a relatively low frequency compared to the figures reported by the French national college of obstetricians and gynecologists [16] which considers that the anomaly of the fetal heart rate is the main indication for instrumental extractions mentioned in the literature. The difference in indications is explained by an early diagnosis of acute fetal suffering in developed countries promoted by labour monitoring methods such as recording fetal heart rate, fetal blood $\mathrm{pH}$ after scalp micropuncture. In our African context, we use clinical means such as auscultation of fetal heart sounds through Pinard's stethoscope and the appearance of amniotic fluid.

\subsection{Prognostic aspects}

\section{Maternal Prognosis}

In our study, episiotomy was performed in $97.3 \%$ of parturient women.

Authors such as Troyer [15] and Randram bliololona in Madagascar [20] also reported relatively comparable percentages with $96 \%$ and $79.25 \%$ respectively.

Our results are consistent with the data in the literature. Anglo-Saxon authors recommend episiotomy for almost all births in primiparous women; this seems excessive according to many French authors who argue that flexible perineas are possible in some primiparous women [21].

Maternal complications were dominated by 3 perineal tears (3.2\%) and 1 case of perineal tear associated with postpartum hemorrhage (1.3\%). We did not observe any cervical tears in our study. The prevalence in the literature of cervical tears is low after instrumental extraction, ranging from $0 \%$ to $3 \%$ [11] [22] [23]. One cohort study found an increased risk after a forceps (odds ratio of 2.2), but not after the suction cup [24]. These tears are related to a poor appreciation of expansion, the forceps or suction cup being applied to incomplete expansion as supported by Cissé [7]. With regard to postpartum hemorrhage, several cohort studies have shown a significant increase in hemorrhagic risk after instrumental extraction compared to the spontaneous lower route (Odds ratio ranging from 1.66 to 2.40$)$ [25] [26].

The reasons given are the increased risk of soft tissue tears and uterine atonypromoted by the presence of associated factors such as dystocic labour, prolonged second phase and macrosomy. Two cohort studies, one Dutch with 3,434 [27] and one French with 19,182 [28], did not find that instrumental extraction was a significant risk factor for the severity of postpartum hemorrhage. In short, everything depends on the conditions of application and the perfect mastery of the 
extraction technique by the midwife [29] [30].

\section{Neonatal Prognosis}

In our series, the majority of newborns had a good Apgar score (96\%), a rate globally comparable to that noted in our cesarean deliveries as reported by Johnson in Thailand [31]. This observation, which is also found in the literature [7] [11] [32], shows that instrumental extraction does not increase the risk of neonatal suffering if the conditions of application are respected, if the indications are well established and if the technique is perfectly mastered. The neonatal mortality rate recorded in our series is 2 cases $(0.4 \%)$ of live births. These results are comparable to those currently reported in the literature by Cissé and Ndiaye, which range from $0.3 \%$ to $0.5 \%$ live births [7] [8] [9]. It confirms the improvement in the neonatal prognosis of instrumental extractions. The neonatal lesion essentially found in our series was the caput succedaneum in 2 cases $(2.1 \%)$, a minor lesion that is not specific to instrumental extractions [33].

\section{Conclusion}

Instrumental extractions are less and less practiced in our maternities. The indications of these maneuvers must be well posed and the conditions of achievements well respected to avoid failures and materno-fetal complications.

\section{Limitations of the Study}

This was a retrospective study and some files were not sufficiently informed.

\section{Conflicts of Interest}

The authors declare no conflicts of interest regarding the publication of this paper.

\section{References}

[1] Lansac, J., Hanrion, C. and Body, G. (1992) Instrumental Extractions: Forceps, Spatulas, Suction Cups. In: Practice of Childbirth, 6th Edition, Simep, Paris, 104-105.

[2] William, M.C. (1991) A Randomized Comparison of Assisted Vaginal Delivery by Obstetric Forceps and Polyethylene Vacuum Cup. Obstetrics \& Gynecology, 78, 789-794.

[3] Lansac, J., Descamps, P. and Oury, J.F. (2001) Practice of Childbirth. 5th Edition, Masson, Paris, 53.

[4] Hankins, G.D.V. and Rowe, T.F. (1996) Operative Vaginal Delivery. American Journal of Obstetrics \& Gynecology, 175, 275-282. https://doi.org/10.1016/S0002-9378(96)70135-7

[5] O'Grady, J.P., Pope, C.S. and Hoffman, D.E. (2002) Forceps Delivery. Best Practice \& Research: Clinical Obstetrics \& Gynaecology, 16, 1-16. https://doi.org/10.1053/beog.2002.0251

[6] Ndao, D. (2007) Forceps Deliveries in Senegal: Results of Three Surveys on Obstetric and Surgical Coverage. Thesis Med Dakar, n 03.

[7] Cisse, C.T., Ewagnignon, E., Fotso, A., Maitournam, F., Moreau, J.C. and Diadhiou, F. (1998) Indications and Prognosis for Delivery by Forceps at the Dakar University 
Hospital Center. Dakar Medical, 43, 92-99.

[8] Diouf, A.B. (2010) Epidemiology and Prognosis of Instrumental Extractions at the Maternity Unit of the Dakar Institute of Social Hygiene. Mémoire DES, No. 258, Dakar, 3 p.

[9] NdiayeTraoré, A. (1992) Statistical and Epidemiological Assessment of Obstetric and Gynecological Emergencies at the Dakar University Hospital Center. Journal of Medical Thesis, 6, 51-53.

[10] Ekoundnzola, J.R., Buambo, S., Nkihouabonga, G. and Nayanda, H.F. (2001) Forceps in Africa: About 138 Applications at the Brazzaville Teaching Hospital. Médecine $d$ Afrique Noire, 48, 472-476.

[11] Boni, S., Abauleth, R., Gondo, D., Koffi, A., Effoh, D. and Kone, N. (2005) Indications of Instrumental Extractions and Fetal-Maternal Prognosis at Cocody University Hospital. J from SAGO, 6(1).

[12] Ben Assia, N., Gara, M.F., Yazidi, M. and Battar, S. (2003) Forceps Delivery: Indications and Maternal-Fetal Morbidity. Medical Tunisia, 81, 180-183.

[13] MSAS-UNICEF-WHO CEFOREP (2014) Assessment of Obstetric and Neonatal Emergency care Needs in Senegal 2012-2013. Dakar Report, December, 17 p.

[14] Sow, D.B. (2013) Prognosis of Vacuum Delivery at the Pikine National Hospital Center. Thèse Med Dakar, No. 99, (3).

[15] Troyer, J., Bouvenot, J., Ercole, C. and Boubli, L. (2005) Instrumental Extraction by Thierry's Spatulas about 166 Cases. Journal of Gynecology Obstetrics and Human Reproduction, 34, 795-801. https://doi.org/10.1016/S0368-2315(05)82956-4

[16] National College of French Obstetrician Gynecologists (2009) Text of Recommendations. Instrumental Extracts. La Revue Sage-Femme, 8, 104-107. https://doi.org/10.1016/j.sagf.2009.02.004

[17] Berku, M., Ramamurthy, R. and O'Connor, P. (1995) Cohort Study of Silastic Vacum Cup Deliveries: Safety of the Instrument. Gynécologie Obstétrique \& Fertilité, 66, 503-509.

[18] Dumont, M. (1994) Do the Romans Know the Forceps? Journal of Gynecology Obstetrics and Human Reproduction (Paris), 23, 834-835.

[19] Cisse, C.T., et al. (2015) Indications and Prognosis of Instrumental Fetal Extractions. African Journal of Surgery, 3, 186-191.

[20] Randriambololona, D.M.A. (2015) Materno-Fetal Complications of Instrumental Extractions by Forceps and Vacuum Extraction. JMGO, 1, 7-11.

[21] Sadoul, G. (1986) Trauma to the Lower Genital Tract and Perineum Following Childbirth. Medical and Surgical Encyclopedia Obstetrics Gynecology and Reproductive Biology (Paris, France). 5.

[22] Baume, S., Cheret, A., Creveuill, C., Vardon, D., Herlicoviez, M. and Dreyfus, M. (2004) Complications of Vacuum Assisted Births. Journal of Gynecology Obstetrics and Human Reproduction, 33, 304-311. https://doi.org/10.1016/S0368-2315(04)96459-9

[23] Combs, C.A., Murphy, E.L. and Lavos, R.K. (1991) Factors Associated with Postpartum Hemorrhage with Vaginal Birth. Obstetrics \& Gynecology, 77, 69-76.

[24] Gardella, C., Taylor, M., Benedetti, T., Hitti, J. and Critchlow, C. (2001) The Effect of Sequential Use of Vacuum and Forceps for Assisted Vaginal Delivery on Neonatal and Maternal Outcomes. Transactions of the Twenty-First Annual Meeting of the Society for Maternal-Fetal Medicine, 185, 896-902.

[25] Demissie, K., Rhoads, G.G., Smulian, J.C., Bbalasubramania, B., Joseph, K.S. and 
Kramer, M. (2004) Operative Vaginal Delivery and Neonatal and Infant Adverse Outcomes: Population Based Retrospective Analysis. BMS, 329, 1-6. https://doi.org/10.1136/bmj.329.7456.24

[26] Sheiner, E., Sarid, L., Lery, A., Seidman, D.S. and Hallak, M. (2005) Obstetric Risk Factors an Out of Pregnancies Complicated with Early Postpartum Hemorrhage: A Population-Based Study. The Journal of Maternal-Fetal \& Neonatal Medicine, 18, 149-154. https://doi.org/10.1080/14767050500170088

[27] Schaal, J.P., Riethmuller, D. and Menget, A. (2004) Ventouse Obstétricale. Encyclopédie Medicochirurgicale Gynécologie Obstétrique, 1, 156-179. https://doi.org/10.1016/j.emcgo.2004.02.005

[28] Plauché, W.C. (1979) Fetal Cranial Injuries Related to Delivery with the Malmstrom Vacuum Extractor. Obstetrics \& Gynecology, 53, 750-757.

[29] Kamal, H. (1985) Place of the Forceps in Current Obstetrical Practice at the CHU of Rabat. Thesis Med Rabat, No. 42.

[30] Murphy, D.J. (2003) Cohort Study of Operative Delivery in the Second Stage of Labor and Standard in Obstetric Care. BJOG, 110, 610-615.

https://doi.org/10.1046/j.1471-0528.2003.01463.x

[31] Johnson, J.H., Figueroa, R., Garry, D., Elimian, A. and Maulik, D. (2004) Immediate Maternal and Neonatal Effects of Forceps and Vacuum Assisted Deliveries. Obstetrics \& Gynecology, 103, 513-518. https://doi.org/10.1097/01.AOG.0000114985.22844.6d

[32] Riethmuller, D., Schaal, J.P. and Maillet, R. (2001) Obstetric Suction Cup: A Modern Instrument. Gynécologie Obstétrique \& Fertilité, 29, 648-661. https://doi.org/10.1016/S1297-9589(01)00205-3

[33] Laurie, S., Glezerman, M. and Sadan, O. (2005) Maternal and Neonatal Effects of Forceps and Vacuum Operative Delivery. International Journal of Gynecology \& Obstetrics, 89, 293-294. https://doi.org/10.1016/j.ijgo.2005.02.007 